\title{
Gastrointestinal Parasite Infection in Cats in Daegu, Republic of Korea, and Efficacy of Treatment Using Topical Emodepside/Praziquantel Formulation
}

\author{
Seung-Hun Lee ${ }^{1,2}$, Younsung Ock ${ }^{3}$, Donghag Choi ${ }^{3}$, Dongmi Kwak,* \\ 'College of Veterinary Medicine, Kyungpook National University, Daegu 41566, Korea; ${ }^{2}$ National Research Center for Protozoan Diseases, Obihiro \\ University of Agriculture and Veterinary Medicine, Obihiro, Hokkaido, Japan; ${ }^{3}$ Dongin Veterinary Clinic, Daegu 41946, Korea
}

\begin{abstract}
The purpose of this study was 2-fold: 1) to investigate the prevalence of gastrointestinal parasite infection in cats reared in Daegu, Republic of Korea and 2) to assess the efficacy and safety of a topical emodepside/praziquantel formulation for cats with parasitic infections. The gastrointestinal parasite infections were examined microscopically using the flotation method. Of 407 cats, 162 (39.8\%) were infected by at least one gastrointestinal parasite, including Toxocara cati (63.0\%), Toxascaris leonina (31.5\%), Taenia taeniaeformis (3.7\%), and Cystoisospora felis (1.9\%). None of the infected animals had multiple infections. When the data were analyzed according to sex, age, and type of cat, stray cats showed statistically higher prevalence than companion cats $(P<0.05)$. On the 5th day after treatment, no parasitic eggs were detected using microscopic examination. In addition, no adverse effects, such as abnormal behaviors and clinical symptoms, were observed in the cats treated with the drug. These results quantify the prevalence of gastrointestinal parasites in cats in Daegu, Republic of Korea, and show that topical emodepside/praziquantel is a safe and effective choice for treating the parasitic infections in cats.
\end{abstract}

Key words: Anthelmintic, fecal examination, feline, gastrointestinal parasite

\section{INTRODUCTION}

Cats are susceptible to various gastrointestinal parasites, including Nematoda (Toxocara spp., Aelurostrongylus abstrusus, Strongyloides spp., and Ancylostoma spp.), Trematoda (Clonorchis sinensis and Paragonimus spp.), Cestoda (Taenia taeniaeformis, Spirometra mansoni, Diphyllobothrium spp., and Echinococcus multilocularis), Coccidia (Cystoisospora spp., Toxoplasma gondii, Cryptosporidium spp., and Sarcocystis spp.), and Trepomonadea (Giardia duodenalis). Some of these can infect humans as well as animals [1-5]. Of these parasites, infections by helminths are the most common in cats and dogs, despite the availability of numerous effective anthelmintic products [6]. However, less data exist for parasitism on cats than for dogs [7]. In the Republic of Korea, several studies of gastrointestinal parasites in cats are available, however, the studies were done in restricted

- Received 23 November 2018, revised 29 April 2019, accepted 30 April 2019.

*Corresponding author (dmkwak@knu.ac.kr)

(c) 2019, Korean Society for Parasitology and Tropical Medicine

This is an Open Access article distributed under the terms of the Creative Commons Attribution Non-Commercial License (http://creativecommons.org/licenses/by-nc/4.0) which permits unrestricted non-commercial use, distribution, and reproduction in any medium, provided the original work is properly cited. regions, several decades ago $[2,8,9]$. Up-to-date information on gastrointestinal parasite infection in cats is scarce.

Concerning administration routes, topical treatment with anthelmintics is preferred because it is more convenient and less stressful than oral administration for both cats and their owners [10]. Emodepside 2.1\% (w/v) plus praziquantel 8.6\% (w/v) (Profender ${ }^{\circledR}$ spot-on, Bayer, Kiel, Germany) is a topically applied anthelmintic drug with broad-spectrum activity. The product is intended for treatment of gastrointestinal parasites in cats, including nematodes (Toxocara cati, Toxascaris leonina, and Ancylostoma tubaeforme) and cestodes (Dipylidium caninum, T. taeniaeformis, and E. multilocularis). Previous studies showed that the product has high efficacy (>98.5\%) against susceptible gastrointestinal parasites $[4,6]$. Emodepside belongs to a new class of anthelmintic compounds called cyclooctadepsipeptides. It is a derivative of PF1022A, and shows various anthelmintic activities in animals [11]. Praziquantel is a pyrazinoisoquinoline derivative that has shown effectiveness against cestodes in large and small animals [10,12].

The purpose of the present study was to investigate the prevalence of gastrointestinal parasites in cats from Daegu, Republic of Korea, based on microscopic examination. In addition, 
this study evaluated the efficacy and safety of topical emodepside/praziquantel in naturally parasite-infected cats.

\section{MATERIALS AND METHODS}

\section{Sample collection}

Before the study was conducted, written consent was obtained from the owners. Daegu, Republic of Korea, is located at longitude $128^{\circ} 36^{\prime}$ East and latitude $35^{\circ} 52^{\prime}$ North, with a mean annual temperature of $14.1^{\circ} \mathrm{C}$ and a mean annual precipitation of 1,064.4 mm [13]. A total of 407 cat fecal samples were collected from a local veterinary clinic and animal shelter in Daegu, Republic of Korea, from June 2012 to August 2015. The average weight of the cats was $2.2 \mathrm{~kg}$, with a standard deviation of $1.5 \mathrm{~kg}$. The cats selected were classified according to sex (male or female), age (young, <1-year-old; adult, $\geq 1$-yearold), and type of cat (companion or stray cat). The fecal samples were collected from the cages where the cats were kept. The samples were fresh, not dried. After collection, the fecal samples were transported to the College of Veterinary Medicine, Kyungpook National University, Daegu, Republic of Korea, and were stored at $4^{\circ} \mathrm{C}$ until examined microscopically.

\section{Identification of gastrointestinal parasite eggs}

Identification of gastrointestinal parasite eggs from cat fecal samples was based on morphology, using a flotation method with a saturated sodium chloride solution [3]. The severity of infection was judged by the number of parasite eggs, using a modified McMaster method [3]. Eggs per gram of feces (EPG) were calculated and then categorized into three groups: mild, EPG $<1,000$; moderate, $1,000 \leq \mathrm{EPG}<10,000$; severe, $\mathrm{EPG} \geq 10,000$.

\section{Treatment of anthelmintics}

After the fecal examination, cats that were positive for gastrointestinal parasites $(n=162)$ received a single topical application of emodepside/praziquantel (Profender ${ }^{\circledR}$ spot-on), according to the manufacturers' instructions. Cystoisospora felisinfected cats were excluded, because the drug is not considered effective for this species. The treatment was applied to the skin of the cat's neck at the base of the skull while hairs were put aside without shaving.

\section{Evaluation of efficacy and safety}

The efficacy of the emodepside/praziquantel treatment was determined through microscopic examination of gastrointestinal parasite eggs from cat fecal samples, as previously described, five days after treatment. Safety was determined by identification of any behavior abnormalities or clinical symptoms by the veterinarians or owners.

\section{Statistical analysis}

To evaluate statistically significant differences in prevalence as a function of sex, age, or companion/stray status, the Chisquare test was applied using SPSS V.21.0 (IBM Corporation, Armonk, New York, USA). A P-value less than 0.05 was regarded as statistically significant. Also, 95\% confidence intervals were calculated.

\section{RESULTS}

\section{Prevalence of gastrointestinal parasites}

Of the 407 cat fecal samples tested, 162 (39.8\%) were infected by at least one of the gastrointestinal parasites (Table 1). Concerning sex, 76 of 195 male cats (39.0\%) and 86 of 212

Table 1. Prevalence of gastrointestinal parasite infection in cats in Daegu, Republic of Korea, according to sex, age, and type of cat (companion/stray)

\begin{tabular}{|c|c|c|c|c|}
\hline Category & No. of tested & $\begin{array}{c}\text { Positive (\%) with parasitic } \\
\text { infection }\end{array}$ & $95 \% \mathrm{Cl}$ & $P$-value \\
\hline \multicolumn{5}{|l|}{ Sex } \\
\hline Male & 195 & 39.0 & $32.1-45.8$ & 0.743 \\
\hline Female & 212 & 40.6 & $34.0-47.2$ & \\
\hline \multicolumn{5}{|l|}{ Age } \\
\hline Young (<1 year) & 218 & 36.2 & 29.9-42.6 & 0.115 \\
\hline \multicolumn{5}{|l|}{ Type of cat } \\
\hline Companion & 224 & 29.0 & 23.1-35.0 & $<0.001$ \\
\hline Stray & 183 & 39.8 & $45.8-60.2$ & \\
\hline Total & 407 & 39.8 & $35.1-44.6$ & \\
\hline
\end{tabular}


female cats (40.6\%) showed positive fecal samples; the difference in prevalence was not statistically significant $(P=0.743)$. Concerning age, 79 of 218 young cats (36.2\%) and 83 of 189 old cats (43.9\%) showed positive samples; the difference was not statistically significant $(P=0.115)$. Concerning the type of cat, stray cats showed a higher prevalence (97 of 183, 39.8\%) than cats with owners (65 of 224, 29.0\%); this difference was statistically significant $(P<0.001)$.

Based on morphology, T. cati, T. leonina, T. taeniaeformis, and C. felis were identified in $102(63.0 \%), 51(31.5 \%), 6$ (3.7\%), and $3(1.9 \%)$ cat fecal samples, respectively (Fig. 1; Tables 2, 3). When the data were analyzed according to the parasite spe-
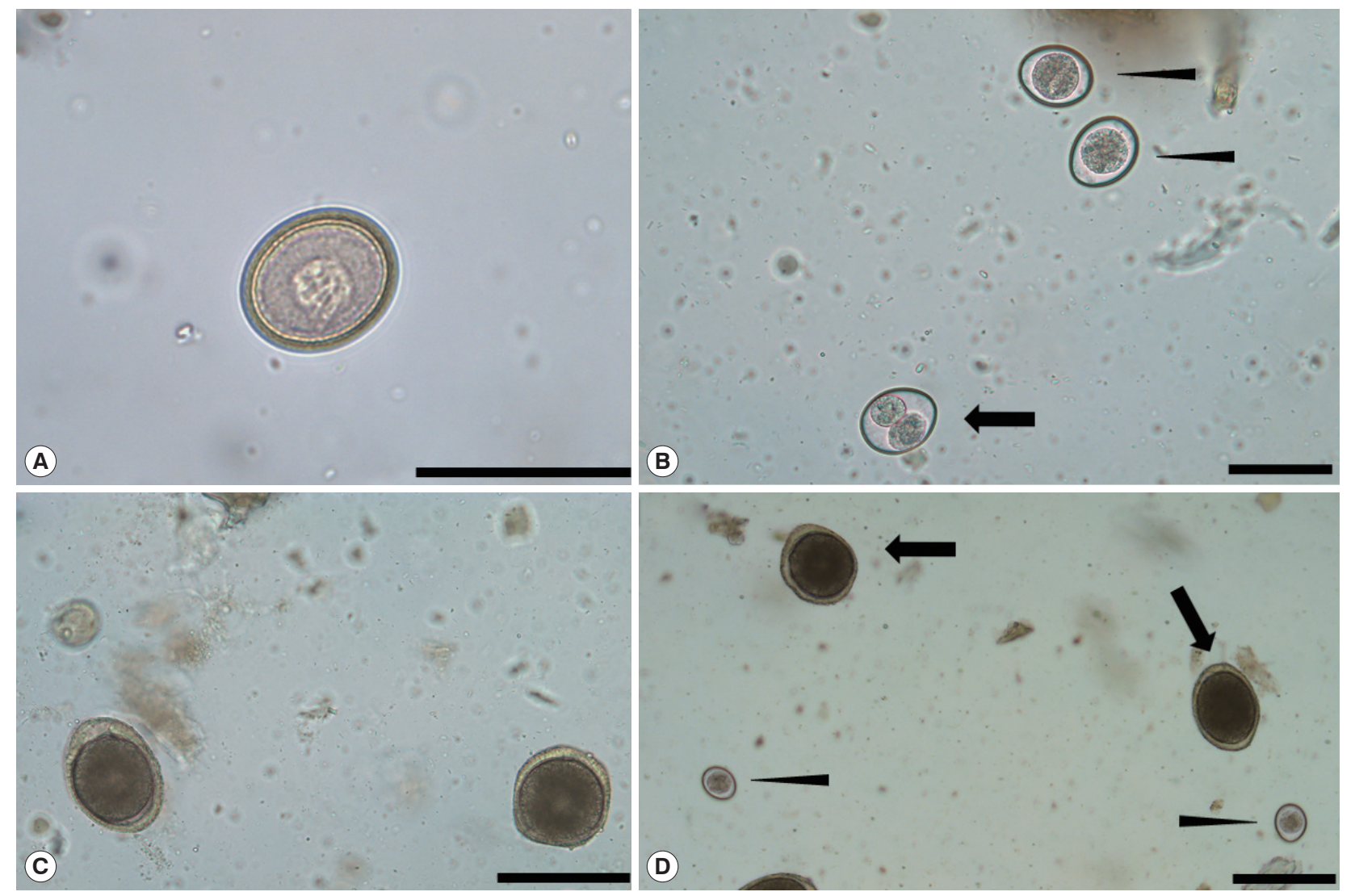

Fig. 1. Eggsand cysts of gastrointestinal parasites in the cats. (A) Taenia taeniaeformis egg. (B) Cystoisospora felis sporulated (black arrow) and unsporulated (black arrow heads) oocysts. (C) Toxocara cati eggs and (D) mixed infection of C. felis (black arrow heads) and T. cati (black arrows). Scale bars $=50 \mu \mathrm{m}$ (A and B) and $100 \mu \mathrm{m}(\mathrm{C}$ and D).

Table 2. Prevalence of gastrointestinal parasite infection in cats in Daegu, Republic of Korea, for the four observed parasite species

\begin{tabular}{|c|c|c|c|c|c|c|c|c|c|}
\hline \multirow{3}{*}{$\begin{array}{l}\text { Parasite } \\
\text { species }\end{array}$} & \multicolumn{9}{|c|}{ Number positive (\%, 95\% Cl) } \\
\hline & \multicolumn{3}{|c|}{ Sex } & \multicolumn{3}{|c|}{ Age } & \multicolumn{3}{|c|}{ Type of cat } \\
\hline & $\begin{array}{c}\text { Male } \\
(n=195)\end{array}$ & $\begin{array}{l}\text { Female } \\
(n=212)\end{array}$ & $P$-value & $\begin{array}{l}\text { Young } \\
(n=218)\end{array}$ & $\begin{array}{c}\text { Adult } \\
(n=189)\end{array}$ & $P$-value & $\begin{array}{l}\text { Companion } \\
(n=224)\end{array}$ & $\begin{array}{c}\text { Stray } \\
(n=183)\end{array}$ & $P$-value \\
\hline $\begin{array}{l}\text { Toxocara } \\
\text { cati }\end{array}$ & $\begin{array}{c}48 \\
(24.6,18.6-30.7)\end{array}$ & $\begin{array}{c}54 \\
(25.5,19.6-31.3)\end{array}$ & 0.842 & $\begin{array}{c}48 \\
(22.0,16.5-27.5)\end{array}$ & $\begin{array}{c}54 \\
(28.6,22.1-35.0)\end{array}$ & 0.128 & $\begin{array}{c}43 \\
(19.2,14.0-24.4)\end{array}$ & $\begin{array}{c}59 \\
(32.2,25.5-39.0)\end{array}$ & 0.003 \\
\hline $\begin{array}{l}\text { Toxascaris } \\
\text { leonina }\end{array}$ & $\begin{array}{c}25 \\
(12.8,8.1-17.5)\end{array}$ & $\begin{array}{c}26 \\
(12.3,7.9-16.7)\end{array}$ & 0.866 & $\begin{array}{c}24 \\
(11.0,6.9-15.2)\end{array}$ & $\begin{array}{c}27 \\
(14.3,9.3-19.3)\end{array}$ & 0.319 & $\begin{array}{c}17 \\
(7.6,4.1-11.1)\end{array}$ & $\begin{array}{c}34 \\
(18.6,12.9-24.2)\end{array}$ & 0.001 \\
\hline $\begin{array}{l}\text { Taenia } \\
\text { taeniaeformis }\end{array}$ & $\begin{array}{c}1 \\
(0.5,0-1.5)\end{array}$ & $\begin{array}{c}5 \\
(2.4,0.3-4.4)\end{array}$ & 0.218 & $\begin{array}{c}4 \\
(1.8,0.1-3.6)\end{array}$ & $\begin{array}{c}2 \\
(1.1,0-2.5)\end{array}$ & 0.690 & $\begin{array}{c}4 \\
(1.8,0.1-3.5)\end{array}$ & $\begin{array}{c}2 \\
(1.1,0-2.6)\end{array}$ & 0.695 \\
\hline $\begin{array}{l}\text { Cystoisospora } \\
\text { felis }\end{array}$ & $\begin{array}{c}2 \\
(1.0,0-2.4)\end{array}$ & $\begin{array}{c}1 \\
(0.5,0-1.4)\end{array}$ & 0.609 & $\begin{array}{c}3 \\
(1.4,0-2.9)\end{array}$ & 0 & 0.252 & $\begin{array}{c}1 \\
(0.4,0-1.3)\end{array}$ & $\begin{array}{c}2 \\
(1.1,0-2.6)\end{array}$ & 0.590 \\
\hline
\end{tabular}


Table 3. Prevalence and intensity of infection of the cats with endoparasites in Daegu, Republic of Korea

\begin{tabular}{lcccc}
\hline \multirow{2}{*}{ Species } & No. (\%) of cats infected & \multicolumn{3}{c}{ Severity (\%) of infection* } \\
\cline { 3 - 5 } & $102(63.0)$ & Mild & Moderate & 10 \\
\hline Toxocara cati & $51(31.5)$ & 41 & 10 & 0 \\
Toxascaris leonina & $6(3.7)$ & 5 & 1 & 0 \\
Taenia taeniaeformis & $3(1.9)$ & 2 & 1 & 0 \\
Cystoisospora felis & 162 & $140(86.4)$ & $22(13.6)$ & 0 \\
Total & &
\end{tabular}

*Mild: $E P G<1,000$; Moderate: 1,000 $\leq E P G<10,000$; Severe: $E P G \geq 10,000$.

cies, there were no statistically significant differences as a function of sex or age $(P>0.05)$; however, $T$. cati and T. leonina both showed significantly higher prevalence in stray cats than in companion cats, with $P$-values of 0.003 and 0.001 , respectively. Most of the cats were mildly infected (140/162; 86.4\%); no severe infections were observed (Table 3). No concurrent infections with two or more parasites were recorded.

\section{Efficacy and safety of the treatment}

At the day 5 after treatment, all the fecal samples were reexamined but no parasite eggs were detected under microscopy. In addition, there were no reports of adverse drug effects, including abnormal behavior or clinical symptoms, from the veterinarians or owners, following administration of the topical treatment.

\section{DISCUSSION}

Feline gastrointestinal parasites have been reported worldwide, but with greatly different prevalence, for example, 39.6\% (71/179) in the USA [14], 58.3\% (271/465) in Argentina [15], $34.3 \%$ (142/414) in Romania [1], 22.8\% $(1,952 / 8,560)$ in Germany [16], 88.5\% (46/52) in Iran [17], 35.1\% (533/1,519) in Europe [7], and 86.3\% (44/51) in Iran [5]. The variability in prevalence seen in these studies might be attributed to differences in sampling region, season, habitat, and the number of samples. In the Republic of Korea, a few decades ago, there were several studies regarding gastrointestinal parasites in cats. In most cases, the studies were restricted to specific regions, and the prevalence varied accordingly, from $75.6 \%$ to $85.6 \%$ $[2,8,9]$.

The overall prevalence of gastrointestinal parasite infections in cats in this study was $39.8 \%(162 / 407)$. The results differed according to age, with adults showing higher prevalence than young cats, but this was not statistically significant $(P=0.115)$. There have been debates regarding the relationship between gastrointestinal infection and age $[5,7,16,17]$, however, each study was based on a different age classification, study region, and sample size; therefore, better-controlled studies are required. Regardless of the debate, the prevalence of gastrointestinal parasites in both young and adult cats indicates a susceptibility to infection in all life stages [5]. There were no significant differences between male and female cats in prevalence. Many previous studies have reported similar observations for different regions $[1,5,17,18]$. Stray cats showed significantly higher prevalence than companion cats, for infections in general as well as for the specific parasite species T. cati and T. leonina. Previous studies targeted at stray cats showed a very high prevalence ( $>85 \%$ ) of gastrointestinal parasites $[2,5,17-19]$, compared to house cats $(<35 \%)[1,7,16]$. The prevalence in stray cats in the present study are not as high as in the previous studies; however, it was significantly higher than in the companion cats. Because the stray cats roamed freely before they were taken to the animal shelter, they had many more chances to be exposed to parasites. It is worth noting that the companion cats, although generally reared inside houses, also showed a high enough prevalence to require regular anthelmintic treatment.

The following parasites were detected in this study: T. cati (63.0\%), T. leonina (31.5\%), T. taeniaformis (3.7\%), and C. felis (1.9\%). The study found that T. cati was the most prevalent parasite, which is consistent with reports of 53.3\% in England [20], 55.2\% in Spain [19], 61.2\% in Argentina [15], 20.3\% in Romania [1], and $28.8 \%$ in Iran [17]. In addition, previous studies in different regions of the Republic of Korea also showed $T$. cati forming the largest fraction of gastrointestinal parasite cases $[2,8,9]$. Two factors may explain the high prevalence of $T$. cati in cats. First, cats often roam freely and discharge eggs of the parasite in the environment, which then contaminate soils [21]. Second, the parasite can be transmitted by breastfeeding, so T. cati-infected maternal cats can pass the infection to their non-infected kittens [22]. In contrast to our 
results showing T. leonina as the second most prevalent helminth in cats, at $30.6 \%$, previous studies reported variable prevalences according to countries (0.1-12.9\%) [16,18,23]. To evaluate accurate prevalence and distribution of $T$. leonina, more samples from different regions and countries are needed because there were not many studies on T. leonina in cats.

In terms of the efficacy and safety of the topical emodepside/praziquantel formulation (Profender ${ }^{\circledR}$ spot-on), the results of this study showed that the drug is safe and effective against gastrointestinal parasites of cats. Five days after applying the treatment, all the gastrointestinal parasites $(n=159)$ yielded negative results in fecal examination, which means that the treatment had high efficacy. In a study conducted using the same treatment, 100\% efficacy was recorded against mature and immature A. tubaeforme in domestic cats [24]. According to Reinemeyer et al. [25], this emodepside/praziquantel topical solution is effective against all stages of T. cati, yielding 100\% efficacy against both mature and immature adults. Compared to oral adminstration of anthelmintics, topical application is more convenient, especially for cats [26].

In conclusion, the results in this study showed that gastrointestinal parasites in cats in Daegu, Republic of Korea, are prevalent and T. cati forming the largest portion of cases. The high prevalence of gastrointestinal parasites in cats suggests a possibility that cats are easily exposed not only to gastrointestinal parasites but also other pathogens, emphasizing the need for regular medical check-ups. In addition, treatment of gastrointestinal parasites in cats using emodepside/praziquantel formulation showed high safety and efficacy.

\section{CONFLICT OF INTEREST}

The authors report no conflict of interest related to this study.

\section{REFERENCES}

1. Mircean V, Titilincu A, Vasile C. Prevalence of endoparasites in household cat (Felis catus) populations from Transylvania (Romania) and association with risk factors. Vet Parasitol 2010; 171 : 163-166.

2. Sohn WM, Chai JY. Infection status with helminthes in feral cats purchased from a market in Busan, Republic of Korea. Korean J Parasitol 2005; 43: 93-100.

3. Taylor MA, Coop RL, Wall RL. Laboratory diagnosis of parasitism. In Taylor MA, Coop RL, Wall RL eds, Veterinary Parasitolo- gy. 4th ed. Chichester, UK. Wiley Blackwell. 2016, pp 259-312.

4. Traversa D, Milillo P, Di Cesare A, Lohr B, Iorio R, Pampurini F, Schaper R, Bartolini R, Heine J. Efficacy and safety of emodepside $2.1 \%$ /praziquantel $8.6 \%$ spot-on formulation in the treatment of feline aelurostrongylosis. Parasitol Res 2009; 105 (suppl): 83-90.

5. Yakhchali M, Hajipour N, Malekzadeh-Viayeh R, Esmaeilnejad B, Nemati-Haravani T, Fathollahzadeh M, Jafari R. Gastrointestinal Helminths and Ectoparasites in the Stray Cats (Felidae: Felis catus) of Ahar Municipality, Northwestern Iran. Iran J Parasitol 2017; 12: 298-304.

6. Wolken S, Böhm C, Schaper R, Schnieder T. Treatment of thirdstage larvae of Toxocara cati with milbemycin oxime plus praziquantel tablets and emodepside plus praziquantel spot-on formulation in experimentally infected cats. Parasitol Res 2012; 111: 2123-2127.

7. Beugnet F, Bourdeau P, Chalvet-Monfray K, Cozma V, Farkas R, Guillot J, Halos L, Joachim A, Losson B, Miró G. Parasites of domestic owned cats in Europe: co-infestations and risk factors. Parasit Vectors 2014; 7: 291.

8. Huh S, Sohn WM, Chai JY. Intestinal parasites of cats purchased in Seoul. Korean J Parasitol 1993; 31: 371-373.

9. Yang HJ, Park TW, Cheon SJ, Yoon YB, Kim NJ, Park BK, Kim CS. Internal parasites of cats in Iri and its vicinity. Korea J Vet Serv 1995; 18: 33-40 (In Korean).

10. Altreuther G, Buch J, Charles SD, Davis WL, Krieger KJ, Radeloff I. Field evaluation of the efficacy and safety of emodepside/praziquantel spot-on solution against naturally acquired nematode and cestode infections in domestic cats. Parasitol Res 2005; 97 (suppl): 58-64.

11. Harder A, von Samson-Himmelstjerna G. Cyclooctadepsipeptides--a new class of anthelmintically active compounds. Parasitol Res 2002; 88: 481-488.

12. Arion A, Fernández-Varón E, Cárceles CM, Gagyi L, Ognean L. Pharmacokinetics of praziquantel and pyrantel pamoate combination following oral administration in cats. J Feline Med Surg 2018; 20: 900-904.

13. Korea Meteorological Administration. Annual Climatological Report. Seoul, Korea. Korea Meteorological Administration. 2010, pp 14-15.

14. Carleton RE, Tolbert MK. Prevalence of Dirofilaria immitis and gastrointestinal helminths in cats euthanized at animal control agencies in northwest Georgia. Vet Parasitol 2004; 119: 319-326.

15. Sommerfelt IE, Cardillo N, López C, Ribicich M, Gallo C, Franco A. Prevalence of Toxocara cati and other parasites in cats' faeces collected from the open spaces of public institutions: Buenos Aires, Argentina. Vet Parasitol 2006; 140: 296-301.

16. Barutzki D, Schaper R. Results of parasitological examinations of faecal samples from cats and dogs in Germany between 2003 and 2010. Parasitol Res 2011; 109: 45-60.

17. Borji H, Razmi G, Ahmadi A, Karami H, Yaghfoori S, Abedi V. A survey on endoparasites and ectoparasites of stray cats from Mashhad (Iran) and association with risk factors. J Parasit Dis 
2011; 35: 202-206.

18. Zibaei M, Sadjjadi SM, Sarkari B. Prevalence of Toxocara cati and other intestinal helminths in stray cats in Shiraz, Iran. Trop Biomed 2007; 24: 39-43.

19. Calvete C, Lucientes J, Castillo JA, Estrada R, Gracia MJ, Peribáñez MA, Ferrer M. Gastrointestinal helminth parasites in stray cats from the mid-Ebro Valley, Spain. Vet Parasitol 1998; 75: 235-240.

20. Nichol S, Ball SJ, Snow KR. Prevalence of intestinal parasites in feral cats in some urban areas of England. Vet Parasitol 1981; 9: 107-110.

21. Mikaeili F, Mirhendi H, Hosseini M, Asgari Q, Kia EB. Toxocara nematodes in stray cats from shiraz, southern iran: intensity of infection and molecular identification of the isolates. Iran J Parasitol 2013; 8: 593-600.

22. Parsons JC. Ascarid infections of cats and dogs. Vet Clin North Am Small Anim Pract 1987; 17: 1307-1339.

23. Miró G, Montoya A, Jiménez S, Frisuelos C, Mateo M, Fuentes I.
Prevalence of antibodies to Toxoplasma gondii and intestinal parasites in stray, farm and household cats in Spain. Vet Parasitol 2004; 126: 249-255.

24. Altreuther G, Borgsteede FHM, Buch J, Charles SD, Cruthers L, Epe C, Young DR, Krieger KJ. Efficacy of a topically administered combination of emodepside and praziquantel against mature and immature Ancylostoma tubaeforme in domestic cats. Parasitol Res 2005; 97 (suppl): 51-57.

25. Reinemeyer CR, Charles SD, Buch J, Settje T, Altreuther G, Cruthers L, McCall JW, Young DR, Epe C. Evaluation of the efficacy of emodepside plus praziquantel topical solution against ascarid infections (Toxocara cati or Toxascaris leonina) in cats. Parasitol Res 2005; 97 (suppl): 41-50.

26. Böhm C, Wolken S, Schnyder M, Basso W, Deplazes P, Di Cesare A, Deuster K, Schaper R. Efficacy of Emodepside/Praziquantel Spoton (Profender ${ }^{\circledR}$ ) against adult Aelurostrongylus abstrusus nematodes in experimentally infected cats. Parasitol Res 2015; 114: 155-164. 